\title{
Design of Banknote Withdrawal System of Supermarket Automatic Change Machine
}

\author{
Wang Haiyan ${ }^{1}$, Wang $\mathrm{Na}^{2}$, Jiang Yunchun ${ }^{3}$, Yang Jingsong ${ }^{4}$ \\ Qingdao Huanghai University Qingdao China \\ E-mail: 541101645@qq.com
}

\begin{abstract}
The paper mainly designs the banknote withdrawal system of supermarket automatic change machine. The system mainly includes the banknote box, banknote separation, banknote flow path, laser thickness gauge, fault separation switch, waste banknote collection box. The system mainly uses the method of fiction withdrawal to separate the banknote by the difference of the friction force, then flows into the laser thickness gauge through the banknote flow path, and controls the final flow of the banknote by the fault separation switch finally. The structure is compact, the occupied space is less, it is suitable for the use of the supermarkets, improves the accuracy and efficiency of change. It can change among a variety of denomination banknotes automatically, and reduces payment time, so as to relieve the shopping queuing situation.
\end{abstract}

Keywords: Automatic Change; Banknote Withdrawal System; Finite Element Analysis; Laser Detection

\section{Introduction}

At present, cash register used in China's supermarket does not have the function of automatic change, research about the supermarket automatic change machine is relatively lack. The requirements for the customer and the cost is high to the supermarket automatic cash register used in researched abroad, which does not solve the problem of long queuing time for customers. Consumers need cash register to improve efficiency, shorten the queuing time, and supermarkets need to improve work efficiency, increase the output of the product, increase sales. The banknote withdrawal system of automatic change machine will make up for the lack of traditional banknote register, to reduce the labor intensity of the staff and facilitate the use of the supermarket.

\section{The choice of the banknote withdrawal method}

The banknote withdrawal method in traditional banknote register mainly includes vacuum suction and friction withdrawal. Comprehensive comparison of the advantages and disadvantages of these two methods of banknote withdrawal, combined with the actual needs of the supermarket automatic change machine, choose the friction withdrawal which pays quickly, low cost, and technology perfect. This device is compact, occupies less space, widely used in ATM machines and bank tellers machines with a higher use proportion.

\section{Design principle of parallel banknote withdrawal}

The system is a combination of six denominations change, respectively50 yuan, 20 yuan, 10 yuan, 5 yuan, 1 yuan, 0.5 yuan. First find the amount of $\mathrm{X}$ yuan by the money paid by customer minus the amount scanned by cashier, and then make $\mathrm{X} / 50$, take its integer N1, N1 is the number of banknote that should get out from 50 yuan single machine, Take the remainder M1, then make M1 / 20 and so on, until the change is completed. And finally the customers receive balance by themselves, the cashier is only responsible for the dress of goods. It can improve work efficiency and reduce queuing time by this way. 


\section{The main component of banknote withdrawal system}

The banknote withdrawal system of supermarket automatic change machine consists of banknote box, banknote separation, banknote flow, laser detection, fault separation, waste banknote collection and other modules. First, the staff put the whole stack of flattened banknotes into the banknote box in accordance with the different denomination, the banknote box provides banknote and adjusts pressure, and then the top of the banknotes achieve the separation of single banknote through the effect of twister, stripping wheel, guide wheel. The banknotes flow into the laser detection device through banknote flow path to verify whether the banknote withdrawal is correct. If the banknotes withdrawal are correct, the banknotes will flow out automatically and achieve automatically change. If the banknote withdrawal is wrong, the laser detection device will command the splitter open, the banknotes will flow into the waste banknote box, and the banknotes withdrawal device will be ordered again to be reimbursed until the banknote withdrawal is correct.

The system is a parallel integration of different denomination, so that it can achieve any match with different denominations and change automatically. The overall structure is shown in Fig.1.

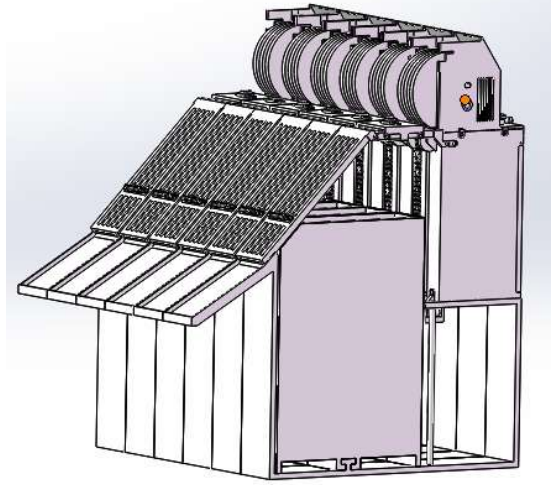

Fig. 1 Overall structure

(1) Design of banknote box module

The banknote box module is mainly composed of four parts: banknote box, banknote pallet, dispenser screw and the pressure sensor, to completes the banknote supply, the pressure detection, the pressure regulation and so on.

Automatic change machine needs to set up a special banknote storage device when used, in order to facilitate the storage of the change. The banknote box in this design replaces the work content of the banknote pressure push plate, banknote pallet and pressure adjustment spring in the traditional ATM machine, to achieve banknote storage, banknote feeding, banknote keeping, pressure adjustment and other functions.

The main function of the banknote pallet is to lift the whole stack of banknote, while controlling the feeding of the whole stack of banknote. A part of the banknote pallet is placed inside the box, and the other part is engaged with the lead screw. The rise and fall of the pallet are realized by positive and the reverse rotation of the screw. Screw drive have the features of high transmission efficiency (generally $0.20 \%-0.40 \%$ ), high transmission accuracy, smooth movement and so on. The top banknotes contact with the pressure sensor on the top of the banknote box to detect the pressure value of the top banknotes in real time. The banknote pallet increases or decreases the top pressure by increasing and lowering the top pressure, so that the top pressure can be controlled in a suitable interval to ensure the efficiency of the banknote.

When the top pressure is too small, the pressure sensor collects the pressure data and sends a forward signal to the motor. Under the coupling of the coupling, the lead screw is rotated forward and the banknote pallet is moved upwards to increase the pressure of the top banknote finally. When the top pressure is too large, the pressure sensor collects the pressure data and sends a reverse signal to the motor. By the coupling, the lead screw is reversed and the banknote pallet is moved downwards to reduce the pressure of the top banknotes. The Specific feedback structure is shown in Fig.2. 


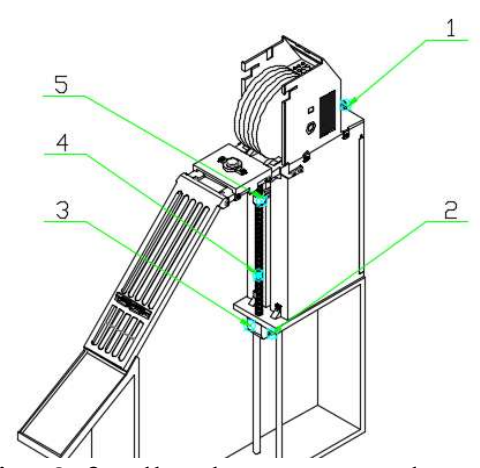

Fig. 2 feedback structure drawing

1-pressure sensor; 2-motor; 3-coupling; 4-lead screw; 5-banknote pallet

(2)Design of friction banknote modular

Friction banknote structure is widely used in ATM machines and bank tellers machine, the banknotes can be divided into three stages: twisting banknote, peeling adhesive banknote and banknotes input. The stage of twisting banknotes is the process of twisting the banknote from the whole stack of banknotes by the twister. In the process of twisting, the pressure sensor detects the positive pressure of the paper money, if the pressure is too large, it will not twist the banknote, while the pressure is too small, it will cause the friction is too small between the twister and the top banknote, and fail to banknotes withdrawal.

Peeling adhesive banknote stage: If the positive pressure provided by the banknote pallet is too large or the banknote is adhesive during the normal operation of the twister, there is often a problem that multiple banknotes are twisted at the same time. The excess banknotes are returned to the banknote box by reversal peeling wheel, and the returned banknotes are twisted again at the next time. When the banknote is peeled off, the pressure between the twister and the peeling wheel should be controlled within a certain range.

Banknote input stage: The banknotes are twisted by the fiction paper money, and flow into the path through the guide plate and the guide wheel. The guide plate is used to prevent banknote from twisting out of the mechanism, and the guide wheel can be used to control the flow of the banknotes and to provide forward power. Under the combined action of the guide wheel and the guide plate, the banknotes enter the banknote path along the normal track.

(3)Design of laser thickness measurement module

When there is a foreign matter between the banknotes, and the adhesion strength is large, it will lead that peeling wheel fail to peel off banknote normally, finally occur overlapping phenomenon. this special phenomenon will cause greater loss, laser thickness module is designed in order to avoid such problems.

The laser thickness gauge cooperates with the banknote flow path, mainly consists of the up and down laser sensors, design model is shown in Fig.3. The laser sensors measure the banknote position of the up and down surfaces by shooting, and then calculate the thickness of the measured body to infer whether the banknote is normal. When the banknote withdrawal is normal, the shunt switch is in the normally closed state. when the banknote withdrawal is abnormal, the laser thickness gauge sends a signal to the magnetic sensor, magnetic sensor will power and produce magnetic force, so as to attract the shunt switch open, complete the shuffle of the waste banknotes. The flow path structure of banknote withdrawal is shown in fig. 4 .

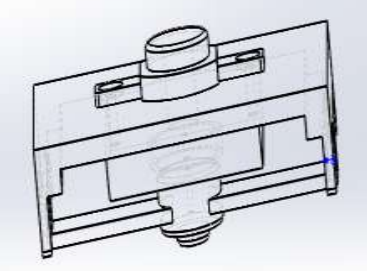

Fig. 3 laser thickness gauge model 


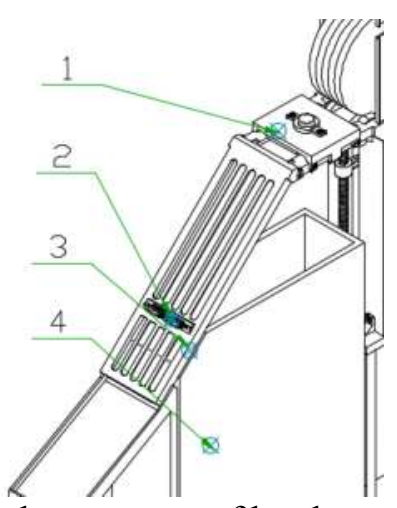

Fig. 4 flow path structure of banknote withdrawal

1- laser thickness gauge; 2 - magnetic induction coil; 3 - shunt switch; 4 - waste banknote box (4)Design of waste banknote collection module

The waste banknote collection device is used to collect the abnormal banknotes, which mainly composed of the banknote withdrawal flow path, the magnetic induction coil, the shunt switch and the waste banknote box. The waste banknote box is used to store the banknotes that are not normally dispensed, using a pull mechanism. The box is located inside the change machine and can be get from the box. When the supermarket automatic change machine works properly, the shunt switch is closed. When the banknote withdrawal is normal, the shunt switch does not work, the banknote will flow out normally. When the banknote withdrawal is abnormal, the magnetic sensor will power and produce magnetic force, attracts the shunt switch, opens the shunt switch, changes the banknote flow, flows into the waste banknote box.

(5)Selection of motor

The banknote pallet is responsible for the gravity of the whole stack of banknotes in the supermarket automatic change machine, combined with the gravity and security, the maximum positive pressure that the plate can bear should be calculated. Take one- hundred yuan banknote whose area and weight are the largest as the object of the calculation here. The weight $\mathrm{G}$ is $0.15 \mathrm{~g} /$ sheet, the length $\mathrm{L}$ is $155 \mathrm{~mm}$, the width $\mathrm{W}$ is $77 \mathrm{~mm}$, the height $\mathrm{H}$ is $0.1 \mathrm{~mm}$, the height of box storage space $\mathrm{h}$ is $150 \mathrm{~mm}$.

$m=h / H \times 1.15$

$G=m g$

According to the above formulas, the maximum external pressure that the banknote pallet can withstand is $16.9 \mathrm{~N}$, in order to ensure that the motor can achieve the expected working results, the external load pressure is set to $20 \mathrm{~N}$. To ensure that the motor can provide sufficient power and maintain the normal work of the system ,combined with practical needs, select FB-555 DC gear motor. The voltage is $12 \mathrm{~V}$, rated power of $12 \mathrm{~W}$, load current of $1.2 \mathrm{~A}$, speed of $60 \mathrm{r} / \mathrm{min}$.

\section{Finite Element Analysis of Banknote Pallet}

Finite element analysis simulates the real physical system (geometry and load conditions) by mathematical approximation, approximates the infinite unknown real system with a limited unknown quantities. When the finite element analysis of the banknote pallet is carried out, the imported three-dimensional model is discretized to finite points, which reduces the difficulty of calculation and simplifies the process.

The banknote pallets needs to bear the pressure caused by the banknote at work, considering the feasibility and safety of the banknote pallets, The finite element analysis of the banknote pallets is carried out to find out the shortcomings of the design and optimize it. The initial design model of the banknote pallet is shown in Fig.4. The banknote pallets is made of carbon steel, and the banknote pallets' connection part is set to the fixed mode, The upper surface of the banknote pallets is selected as the stress surface, the pressure of $20 \mathrm{~N}$ is applied, The meshed banknote pallet is shown in Fig.5.Finally run this example, the result is shown in Fig.6.

From the figure, a stress concentration phenomenon occurs in the neck position of banknote pallet. It is most likely to be deformed or broken in actual use. The design of the banknote pallet is 
improved, as shown in Fig.7. The ribs are added at the neck position and the back of he banknote pallet, reduce the stress concentration and deformation effectively, improved operation result is shown in Fig. 8.

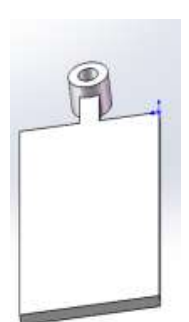

Fig. 4 Initial model

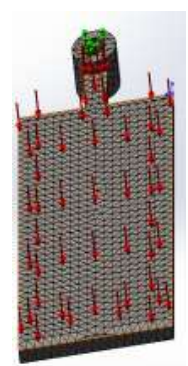

Fig. 5 Grid generation

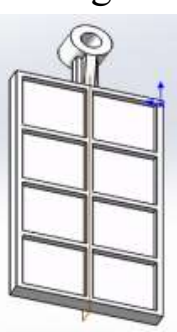

Fig. 7 Improved banknote pallet model

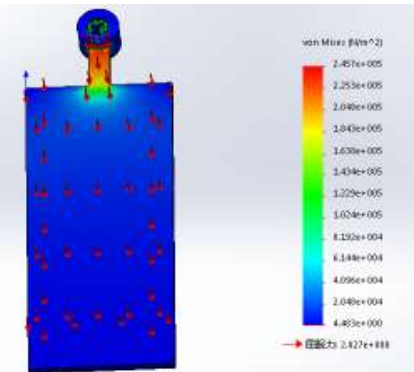

Fig. 6 run result of initial model

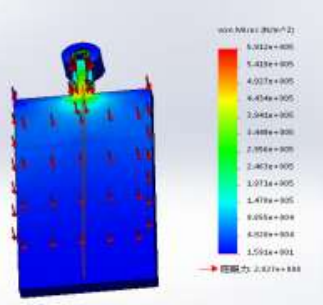

Fig. 8 run result of improved model

\section{Conclusion}

In order to reduce the cashier 's workload and solve the problem of customer queuing long time, the banknote withdrawal system of supermarket automatic change machine is designed on the basis of the traditional checkout counter. The system is mainly composed of banknote box, banknote separation, banknote flow path, laser thickness gauge, fault separation switch, waste banknote collection box and other components. the structure is compact, the occupied space is less. it can achieve automatic change among a variety of denomination banknotes, improves the accuracy and efficiency greatly and suitable for the use and promotion.

\section{References}

[1] Zhang Qiao, Liang Jing, Wang Yanzhi. Teaching Design of Control System of Vending Machine Based on PLC [J]. Science and Technology, 2016,123-125.

[2] Feng Ju. Sensor in the application of ATM [J]. Heilongjiang Science and Technology Information, 2016. 143-145.

[3] Liu Ming, Zhao Zuoxi, Sun Daozong, Liu Xiong, Jin Jundong. Dynamic analysis and simulation of the cash register institutions [J]. Modern Electronics Technique,2015, 124-127.

[4] ZHENG Jun-qiang, HE Lin, TANG Zheng-qiang.Study on Mechanical Behavior of Paper in Vacuum Feeding Technology [J]. Mechanical Design and Manufacture, 2016,98-102. 